\title{
DISCURSO DE PRESENTACION DE LA REVISTA DE DERECHO
}

\author{
SR. Sergio Gómez Nuñez \\ Profesor de Derecho Civil \\ Universidad Católica del Norte \\ Sede Coquimbo
}

Se me ha dispensado la responsabilidad y el honor de presentar y acaso justificar la revista de Derecho, de la Escuela de Derecho de la Universidad Católica del Norte.

Del honor quizá no hay duda; pero en cuanto a la justificación, para ello sólo la historia. $\mathrm{Y}$ en su juicio benévolo no tengo dudas.

Esta historia a la que tan ligada se encuentra esta ciudad que en algunos meses más cumplirá 450 años: la segunda ciudad más antigua de Chile o esta I. Corte que hoy nos alberga en una de sus salas que no ha mucho ya completó 150 años.

Recordemos que esta ciudad como Coquimbo, tan unidos en historia, constituyó un importante polo de desarrollo y un centro comercial y económico relevante y, lo fue, en general lo que hoy constituye la IV región: en la época de la colonia, el puerto y las minas de Punitaquí, luego Brillador y Tamaya. Posteriormente, las primeras fundlciones de cobre que hubo en Chile, debidas a Lambert, enTongoy y Coquimbo; su agricultura, sus primores. Destacados literatos, políticos e intelectuales.

Esta misma actividad justificó la creación de una Corte de Apelaciones en La Serena, para atender las necesidades del norte de Chile. Nació junto con la de Concepción.

Pero las historias de ambas ciudades se separaron. La Universidad de dicha ciudad dio nacimiento a la Escuela de Derecho ya hace muchísimos lustros. La nuestra sólo poco más de un año.

\section{¿Por qué?}

Existiendo en esta región gente de tanta valía.

Fíjense Uds. que desde sus inicios hasta esta fecha la actividad jurisprudencial de nuestros tribunales tiene una destacada importancia, particularmente en materia minera. Históricamente ha sido así. El establecimiento del Código de Minería de 1888 estuvo precedido, en medio de la discusión parlamentaria de una especial petición, que en su parte pertinente transcribo: " Entrando en discusión de este asunto, el señor senador 
don José Clemente Fabres manifestó el deseo de que se oyera la opinión de la lltma. Corte de Apelaciones de La Serena, i formuló indicación en este sentido". La que obviamente fue aceptada recayendo en el Ministro de la I. Corte de La Serena don Sótero Gundián.

De igual manera las proposiciones de destacados juristas de Ovalle en aspectos también mineros, en que destacan don Perfecto Lorca Marcoleta. Y me refiero a ellas, porque son aquellas ventajas comparativas las que han hecho la diferencia.

Recuerden Uds. que la Ley de Efecto Retroactivo de las leyes de 1861 está promulgada con las firmas del Presidente José Joaquín Pérez Mascayano y de Justo, Obispo de La Serena, es decir Justo Donoso, en este entonces Ministro de Justicia, Culto e Instrucción Pública.

Hoy, nuestra región no puede quedar al margen de todo el desarrollo que ha venido experimentando el país.

Estamos actualmente en una situación privilegiada, como pocas regiones del país: hay importante actividad agrícola exportadora, pisquera, portuaria, comercial, turística, pesquera. Tenemos importantes ventajas comparativas. Debemos aprovecharlas, debemos ser creadores, acaso audaces.

Cierto, audaces, pero pedir audacia a los abogados, quizá si uno de los gremios menos dados al cambio por su propia formación. Nuestros propios códigos y nuestra práctica aún está llena de arcaísmos y de fórmulas, que hemos asimilado perfectamente, pero que resultan extrañas y lejanas a quienes las conocen por vez primera.

Nos cuesta mucho aceptar nuevas fórmulas, nuevas cosas: Leasing, contratos de Know How, Franchising. Palabras ajenas, ahora, pero acaso tanto como antaño pudieron serlo la usucapión, la reivindicadora, Warrant, y muchísimas más. Incluso, otras tan propias de la creación popular de esta región como los conceptos de "lluvia" o "sombras", con un profundo contenido jurídico y cuyas transacciones casi todos conocemos.

Nuestra Escuela de Derecho ha surgido precisamente con audacia, pero para aprovechar estas ventajas comparativas que nos otorga la región: Queremos ver al Derecho deambulando en el turismo, en la pesca, en el medio ambiente, en la minería, en la vitivinicultura, en la agricultura, en la integración, en fin, en todo aquello que nos es propio.

Es allí donde podemos, en mayor medida, ser creativos, innovadores. Pero no sólo como Escuela de Derecho, sino en nuestro accionar como abogados, jueces y profesores.

¿y cómo podemos expresarnos? 
De muchos modos y maneras.

Una de ellas es una revista.

Esta revista.

La revista de la Escuela de Derecho.

Cuando me encomendaron esta tarea, me pregunté qué era una revista. Recurrí, por cierto al diccionario: éste dice que Revista es: segunda vista, o examen hecho con cuidado y diligencia, que obviamente apunta efectivamente al fondo, otra es "publicación periódica por cuadernos, con escritos sobre varias materias, o sobre una especialmente", que naturalmente refleja claramente su forma. Ambas cosas es lo que hoy exponemos a Uds.

En general una revista se distingue y separa de un diario por su periodicidad y su contingencia inmediata. Ello hace que la Revista tenga un contenido mas reflexivo. Así, se reserva la denominación de revista para aquellas publicaciones que siendo periódicas y regulares dejan transcurrir mayor lapso de número a número y resulta ser, cronológicamente, anterior al periódico (diario). El artículo de revista es casi siempre un estudio reflexivo, en el que la investigación y el razonamiento se sobreponen a la pasión y a la improvisación.

De igual manera la Revista se engarza con la literatura, y no en vano las incluimos dentro de la literatura jurídica. Y cuando hablamos de literatura jurídica no estamos hablando, ni más ni menos, que de belleza. Ya decía un destacado jurista que la literatura jurídica "es la manifestación artística de la belleza de la verdad jurídica, sentida, conocida y querida por el hombre, y exteriorizada en creaciones individuales por medio de la palabra hablada o escrita"

Es a ello a lo que debemos aspirar, con audacia. Bien sabemos todos, que aún tenemos mucho que decir: Digámoslo. Abramos la discusión jurídica, más allá de la contingencia diaria, rescatemos nuestras inquietudes y expongámosla.

Esta Revista, en particular, ya ha recogido el aporte de magistrados, profesores y abogados. Nos permite conocer parte de la historia del establecimiento de la Escuela de Derecho a través de la presentación que de ella hace su destacada directora doña Luz María Reyes Santelices, reproduce la magistral clase del historiador don Gonzalo Vial Correa, dictada con motivo de la inauguración del primer año académico; contiene destacados trabajos de investigación en materia filosófica, penal, mercantil, laboral, procesal y tributaria y algunas disquisiciones sobre la ley de medio ambiente. En jurisprudencia, se analiza una interesante sentencia sobre el Recurso de Protección emanado de esta lltma. Corte de Apelaciones; contiene una sección de recensiones de libros y un espacio para sus alumnos a través de algunas reflecciones.

Constituye un valioso elemento de difusión, de enseñanza, de entrega para los abogados $y$, especialmente, para los estudiantes que profesionalmente estamos formando. 
Esta Revista, que ha reunido tanto quehacer y esperanza hoy les abre las puertas y les invita a recorrer sus páginas y les espera, para que departan con otros sus experiencias, sus conocimiento, sus inquietudes.

Seamos, pues, generosos y compartamos.

Muchas gracias. 